Special Section:

Cognitive Studies, Theatre, and Performance 



\section{Introduction: Journal of Dramatic Theory and Criticism's Special Section on Cognitive Studies, Theatre, and Performance}

\section{Rhonda Blair and John Lutterbie}

For over a decade theatre and performance scholars and practitioners have been exploring how current research in the cognitive and neurosciences can illuminate understanding and advance our various disciplines. Cognitive sciences began surfacing in theatre and performance studies in the late 1990s. By 2001, papers were being presented at American Society for Theatre Research (ASTR) seminars and articles were appearing in theatre journals and scholarly collections (e.g., Blair's "The Method and the Computational Theory of Mind" in David Krasner's Method Acting Reconsidered - an essay she now finds problematic). ${ }^{1}$ By 2004 there were working groups at both ASTR and the Performance Studies Focus Group preconference of the Association for Theatre in Higher Education (ATHE). The first survey book on the subject, Performance and Cognition: Theatre Studies and the Cognitive Turn, edited by Bruce McConachie and F. Elizabeth Hart, appeared in $2006 .^{2}$ David Saltz edited a special issue of Theatre Journal on "Performance and Cognition" in late 2007. ${ }^{3}$ In 2008 the first full-length monographs were published: McConachie's Engaging Audiences: A Cognitive Approach to Spectating in the Theatre and Blair's The Actor, Image, and Action: Acting and Cognitive Neuroscience. ${ }^{4}$ Palgrave initiated a new series entitled Cognitive Studies in Literature and Performance, under the editorial leadership of McConachie and Blakey Vermeule. A representative sample of recent books includes Amy Cook's Shakespearean Neuroplay: Reinvigorating the Study of Dramatic Texts and Performance through Cognitive Science (2010) and Lutterbie's Toward a General

\footnotetext{
Rhonda Blair is professor of theatre at Southern Methodist University and president of the American Society for Theatre Research (2009-2012). She is author of The Actor, Image, and Action: Acting and Cognitive Neuroscience and editor of a new edition of Richard Boleslavsky's Acting: The First Six Lessons that includes previously unpublished documents from the American Laboratory Theatre (both from Routledge). Her essays appear in Performance and Cognition: Theatre Studies and the Cognitive Turn; Women in American Theatre; Upstaging Big Daddy: Directing Theater as if Race and Gender Matter; TDR: The Drama Review; and Theatre Topics, among others. She makes original performance pieces and directs.
}

John Lutterbie is a professor at Stony Brook University and serves on the board of directors of the Literary Managers and Dramaturgs of the Americas. He is the author of Hearing Voices: Modern Drama and the Problem of Subjectivity (University of Michigan Press) and Toward a General Theory of Acting: Cognitive Science and Performance (Palgrave MacMillan). Other publications have appeared in Upstaging Big Daddy: Directing Theory as if Race and Gender Matter; Performance and Cognition: Theatre Studies and the Cognitive Turn; Theatre Journal; Journal of Psychiatry and the Humanities; and Modern Drama, among others. 
Theory of Acting: Cognitive Science and Performance (2011). ${ }^{5}$

Because the cognitive sciences deal with fundamental aspects of human existence and experience, we believe they can be a useful, even necessary part of the foundation for work in theatre and performance studies. The sciences provide new ways of perceiving the interrelationship of mind and body, new definitions of fundamental categories such as emotion, feeling, and action, and, perhaps more fundamentally, new definitions of "self" and "other." The findings of these sciences place us on the cusp of a paradigm shift. This does not call for us to reject other approaches to theatre and performance studies, but rather it supplements and deepens other methodologies used by our fields, while providing new tools and perspectives. We approach this project with care, mindful of the ease with which research in different fields can be opportunistically misappropriated by those not expert in a given discipline, and mindful of the disagreements and variations among those who are expert, as they tease out and argue about the implications of their findings.

These sciences can support and enrich our appreciation of a whole range of existing performance and theatre theories. Research in neural simulation systems provides evidence of the organic basis for the power of imitation, first argued by Plato and Aristotle. Research in the neural bases of imagination describes a material link between imagination and doing, in ways that both extend and subvert the ideas behind Diderot's model ideal and Stanislavsky's argument for the power of the "magic if." Cognitive linguistics, particularly in terms of blending and compression, takes the meaning of the term "close reading" of dramatic texts to a profound level that allows us to see how texts come from and work through our bodies. Dynamic Systems Theory allows for a model of embodiment that resists the mind/body duality and insists on the interdependency of the individual and the world, while providing insights into the tension between the creative impulse and resistance to change. ${ }^{6}$ The science provides insight into the various aspects of ourselves - intellect, emotion, body - as part of a complex process we call a person, and how we as organisms are inextricably intertwined with each other and our environments.

The umbrella term "cognitive science" encompasses specializations including cognitive psychology, cognitive linguistics, neuroscience, neurolinguistics, and cognitive anthropology, among many others. It is possible to follow two primary paths of development: neuroscience and psychology. Neuroscience's beginnings can be traced to Paul Broca's 1861 discovery of the link between a particular brain area and the capacity for speech. A key event in the founding of psychology as a modern discipline was Wilhelm Wundt's opening of an experimental psychology laboratory in 1879, an innovation that marked a clear separation of psychology from philosophy. Sigmund Freud, who began as a research psychologist, left this work to develop psychoanalysis, publishing The Interpretation of Dreams in 1900. His vocabulary of the unconscious would dominate views of the psyche for decades in 
the US. Shortly thereafter, in 1906, Ivan Pavlov published his findings about reflex responses; his work and that of others, such as Ivan Sechenov, laid the ground for behavioral approaches to psychology that would rival psychoanalytic ones.

Other fields exerted a significant influence on cognitive science at its inception in the mid-twentieth century. Linguistics, established as a discipline in the first decade of the twentieth century, focused on the work of semioticians Ferdinand de Saussure and Charles Sanders Peirce; and, beginning in 1914, Viktor Shklovsky and other Russian literary critics developed a technical approach to the study of poetic language known as formalism. These laid the groundwork for structuralism, a term coined in 1929 by linguist Roman Jakobson, which was to become a basis for the study of language. Computer science (the first freely programmable computer was invented in 1936) and advances in the sophistication and speed with which computers process data led computer scientists to hypothesize that the binary language of computer processes was analogous to the functioning of the human brain. These provided the basis, in the latter half of the $1950 \mathrm{~s}$, on which a group of computer scientists interested in artificial intelligence, psychologists, philosophers, and linguists - most prominently, Noam Chomsky - founded the field of cognitive science to study the acquisition and processing of knowledge that argued against, among other things, the reductive materialism of B. F. Skinner's behaviorism. This first generation cognitive science (roughly the 1950s to the 1980s) developed theories of mind that tended to marginalize physical aspects of how the brain works. This was to become the purview of neuroscience.

At approximately the same time, neuroscientists were identifying physical sources of cognition, discovering more locations in the brain for select functions, learning how, in some cases, brain anatomy could be altered by experience (e.g., the size of string musicians' cortices devoted to the hands is larger than that of nonmusicians), and defining some mechanics of memory function. ${ }^{7}$ By 1970 these neuroscientists had discovered the neurological basis of memory, marked by an alteration in neural structure. By the end of the 1970s, positron emission tomography (PET scans) allowed us to take pictures of activity in the brain. The invention of functional magnetic resonance imagery (fMRI) in 1990 provided images of dynamic neural processes. With the advent of these new technologies, the stunning images, and the promise of scientific and medical advances, neuroscience was thrust center stage. This, along with the human genome project initiated in 1990 and growing interest in Artificial Intelligence-made possible by the increased speed and versatility of computers utilizing parallel processors - gave rise to public interest in the brain. Early arguments that cognitive processes could be explained by the binary codes of computer programs caused a rift between brain researchers who supported this computational model and those who were discovering that neural operations are more complex than can be accounted for by on/off switches.

Perhaps to resist the early and simplistic visions set forth by the prophets 
of computer science, or the science-fiction seductions of William Gibson's Neuromancer, where subjectivity can be downloaded in cyberspace, neuroscientists led by Antonio Damasio began to draw together different scientific findings to form a more complex image of cognition that insisted on the brain as inextricably linked to the body and responsive to the environment. ${ }^{8}$ Speculative texts began to proliferate that encouraged interdisciplinary research, liberating neuroscience from the laboratory, and ushering in what might be called the second generation of cognitive science. This second phase is attempting to identify, among other things, how consciousness arises and its relationship to language, emotion, and our interactions with the world, as an embodied process. Linguist George Lakoff and philosopher Mark Johnson argue that our sense of our bodies, indeed, the fact of being a body, is the source for our major metaphors of thought, meaning, and values, such that, "Much of conceptual inference is, therefore, sensorimotor inference." Cognitive scientists and linguists Gilles Fauconnier and Mark Turner hold a perspective similar to that of Lakoff and Johnson, particularly in the prominence they give to metaphor and image. ${ }^{10}$ Their network model of conceptual integration holds that imagination is the central engine of meaning and that metaphor is central to cognition. They describe how different mental spaces - small conceptual packets, or images, constructed as we think and talk - are integrated in novel ways to help us negotiate our lives. Disparate "inputs" are combined to create new knowledge, insight, or experience that goes beyond that contained in the initial inputs, creating a blended conceptual space. Though blending can be conscious on one level, it operates largely unconsciously; we are not precisely aware of how the blending happens. The discovery of mirror neurons in monkeys in 1996 energized research in neural simulation systems in humans, and generated still more questions about the nature of the self, imitation, empathy, and action.

Though we do not know all of the steps by which "matter becomes imagination" (to use a phrase from neuroscientists Gerald Edelman and Giulio Tononi), how elements of consciousness and behavior relate to brain function is becoming clearer. ${ }^{11}$ Neuroscientist Antonio Damasio comes at the problem of consciousness through his somatic marker hypothesis, "somatic marker" being a term for describing how body-states become linked with conscious responses to or interpretations of them. As with other views cited here, body, feeling, and intellect are viewed as aspects of a single, if complex organic process. In this view, the brain creates strings of associations that arise in the body first as an emotion (here meaning a physiological state of the body), which is translated into a feeling (a conscious "registration" of a body state), which leads to behavior that may or may not be associated with reason or rational thought. These markers become our repertory of responses for guiding reactions to new situations. Particularly pertinent is Damasio's assertion that reason in the fullest sense grows out of and is permeated by emotion, and that emotion is consistently affected by reason and conscious 
cognition. Some neuroscientists theorize that who we are and how we function are based largely upon the development of specific neural patterns, or synaptic connections. Neuroscientist Elizabeth Wilson describes cognitive processing as "the spread of activation across a network of interconnected, neuron-like units," i.e., "Knowledge is implicit, stored in the connections rather than the units," in the paths from neuron to neuron. ${ }^{12}$ From this perspective our sense of our self is at bottom a product of the workings of our synapses, the gaps between our neurons that are bridged by chemicals or an electrical impulse. In this model, nature (genetic make-up) and nurture (experiences) are merely different ways of doing the same thing-wiring synapses in the brain that become manifest as who we are.

This "ecological" or systemic approach to the development and function of cognition is also evident in the work of Edelman and Tononi, who believe that higher brain functions, including consciousness, are conditioned by and require interactions with the world and other people. That is, mind is a result of reciprocal interaction between perceptual and proprioceptive experiences, between external and internal environments, such that what happens in one influences what happens in the other. They hold that only physical processes are needed to explain consciousness, and that consciousness arose only because of a very specific evolution of the physical human body in response to environmental changes both in the natural world and in the organization of human communities. Rejecting the concept of the closed circuits of binary logic as the basis for understanding cognitive processes, embodied cognition is viewed as an open, nonlinear system that is subject to perturbations from an array of different sources. This project has immense implications for our understanding of creativity and the resistance to change, the structure of memory, and of consciousness.

That said, current cognitive science dislocates a number of things, among them familiar constructs of identity, feeling, and selfhood, and the belief that culture and biology are separable_ _ constructs and beliefs that have been dominant for decades. We must, at the same time, be cautious about our applications of the science and honest about our motives for doing so. Science has long informed our engagement with theatre and performance, but there are limits to the relationship and caveats about applications of the former to the latter. Scientists use a reductive approach-verification through repeatable experimentation that accounts for all of the variables involved in the experiment - and an inductive process. In the arts and humanities, theorizing (or, more accurately in terms of science's vocabulary, hypothesizing) is typically deductive. It is based upon the examination of texts and historical artifacts, the observation of performances, or the assessment of the experiential through a particular critical, philosophical, or political framework, and often involves a good degree of subjective interpretation. The inductive nature of science demands that it be reductive, looking at specific, even microscopic objects such as "a single type of neuron in a specific part of the brain." ${ }^{13}$ Underpinning 
the sciences are principles of falsifiability and repeatability. Theories and things presented by science as facts are proven by results that are repeatable, experiment after experiment, and that are always subject to being disproved when a new experiment produces different results. This is, of course, foreign to performance studies' reveling in the complex and contradictory aspects of our objects of study. Interestingly, when scientists bring together the results of a broad range of experiments to reach general conclusions, this brings more variables into play across the experiments and often makes conclusions more speculative, i.e., the broader the assertion, the further scientists move into conjecture and hypothesis and away from science. For this reason, among others, those of us in performance and theatre studies must engage primary and secondary scientific research, which raises the challenge of educating ourselves in the terrain of these sciences and the standards by which they operate. We have found summary articles in recognized journals to be useful points of entry because they provide a context for and condensation of research on particular topics, including competing arguments and claims. We must engage or, at the very least, acknowledge these competing claims if we are to have a hope of being responsible in our appropriations and applications.

Different kinds of evidence, ranging from the neural to the linguistic and behavioral, are useful for different aspects of performance and theatre studies, but cannot be applied whole cloth. Those working with this material have been learning, among other things, the following: First, one must be cautious in using research on the neural level to explain anything in the realm of the experiential or conscious. The discovery of mirror neurons in monkeys, for example, did not immediately mean that humans had mirror neurons or that they functioned identically in humans, or that the discovery of neural simulation in humans meant that we are intrinsically empathetic. Second, one must be clear about what is presented as scientific theory, i.e., an explanation that accounts for observable phenomena, following processes of repeatability and falsifiability. This is different than speculations, which are possible explanations for phenomena which have not yet been borne out by experimentation. It is important to discern between data and conjecture. Third, one must be sensitive to contradictions and disagreements among the scientists' explanations of what they have discovered by experimentation and how they are interpreting it. Fourth, one must be clear about the differences among the various cognitive science disciplines in terms of methodology and parameters for truth claims, e.g., there are differences in the processes and perspectives of cognitive linguists and neuroscientists. Finally, one must be respectful of the power - conscious or otherwise - of metaphor and the intrinsic human tendency to think metaphorically and analogically, or the fact that we "live in the blend," as Amy Cook has written. Sometimes these associational leaps are apt, and sometimes not, growing as they do out of experience, habit, and desire. Having made this last caveat and acknowledging that the use of science qua science can be profoundly important, the use of science as a springboard to engage 
text, space, and performance can be incredibly rich. This potential for creativity and for experiential and intellectual efficacy, however, is different than making a claim that what we do has the efficacy or "truth" of science.

We have selected four essays that deploy a range of cognitive disciplines across theatre and performance studies. In "For Hecuba or for Hamlet: Rethinking Emotion and Empathy in the Theatre," Amy Cook uses cognitive linguistics, embodied cognition studies, and empathy research to engage issues of text and reception, and problems of the nature of feeling in the theatre. Using Hamlet's encounter with the Player King as her starting point, Cook teases out the ways that both embodied cognition and embedded cognition, as informed by culture, function in the theatrical event. The essay unpacks different ways that feeling and empathy work in hearing and viewing a performance, particularly in terms of the different loci of engagement in generating a response in an audience. Wanda Strukus also engages empathy, but does so to explore the nature of audience response to differently-bodied dancers. "Mining the Gap: Physically Integrated Performance and Kinesthetic Empathy" considers the limits of neural simulation and mirroring systems in explaining audience response. Focusing on processes of kinesthetic empathy in audience reception, she uses the work of AXIS Dance Company, composed of normative and disabled dancers (including those in wheel chairs, those with missing limbs, and those with neuromuscular disorders), as a case study for her argument. Through engaging issues of conscious cognition, empathy, and kinesthetic response in the spectators, Strukus challenges us to rethink our sense of identification with the performer, helps us understand how bodily absence or difference works on reception, and complicates any easy or automatic appropriation of the idea of mirror neurons and neural simulation for performance theory. Pil Hansen presents a case study for the application of developmental dramaturgy based on research in memory and imagination. "Perceptual Dramaturgy: Swimmer (68)" describes the process used to develop the performance named in the title, a solo piece based on the Burt Lancaster film. Rethinking dramaturgy through a cognitive lens, Hansen proposes that theories of perception and memory enable the dramaturg to understand the dynamics of actor/director interaction in rehearsal as a means of understanding and suggesting productive categories for artistic choice-making in developing the piece. This process also uses an understanding of how the spectator arrives at an interpretation to anticipate and, perhaps, mold responses in the performance situation. John Emigh draws on the science of neural structures to discuss how a mask archetype that appears in many cultures around the world reflects aspects of somatosensory brain structure. "Minding Bodies: Demons, Masks, Archetypes, and the Limits of Culture" uses findings of cognitive neuroscience to examine the archetype of "the demonic or apotropaic (protective) face as encountered in masks around the world." Drawing on examples from various continents, Emigh considers how the extreme and exaggerated expressions embodied by these masks reflect 
"the proportionate neuronal representation accorded parts of the body within the somatosensory area of the brain's neocortex." In this study of how manifestations of performance may be related to neural mapping and sensory receptors, Emigh posits that the apotropaic mask reflects the very structure of our brain.

We are honored to have been asked to curate this section for the Journal of Dramatic Theory and Criticism. In particular, we appreciate Scott Magelssen's generosity and support throughout the process of working on this project. We hope this collection is a productive support and provocation to further work in applications of cognitive science to theatre and performance.

\section{Notes}

1. Rhonda Blair, "The Method and the Computational Theory of Mind," Method Acting Reconsidered: Theory, Practice, Future, ed. David Krasner (New York: St. Martin's, 2000).

2. Bruce McConachie and F. Elizabeth Hart, Performance and Cognition: Theatre Studies and the Cognitive Turn (New York: Palgrave, 2006). 2007).

3. David Saltz, ed., Special Issue on "Performance and Cognition," Theatre Journal 59.4 (Dec.

4. Bruce McConachie, Engaging Audiences: A Cognitive Approach to Spectating in the Theatre (New York: Palgrave, 2008); Rhonda Blair, The Actor, Image, and Action: Acting and Cognitive Neuroscience (New York: Routledge, 2008).

5. Amy Cook, Shakespearean Neuroplay: Reinvigorating the Study of Dramatic Texts and Performance through Cognitive Science (New York: Palgrave, 2010); John Lutterbie, Toward a General Theory of Acting: Cognitive Science and Performance (New York: Palgrave, 2011).

6. Resources using dynamic systems theory include Evan Thompson, Mind in Life: Biology, Phenomenology, and the Sciences of Mind (Cambridge, MA: Harvard UP, 2007); Shaun Gallagher, How the Body Shapes the Mind (Oxford: Oxford UP, 2005); Alva Noë, Action in Perception (Cambridge, MA: MIT, 2005); Andy Clark, Supersizing the Mind: Embodiment, Action, and Cognitive Extension (Oxford: Oxford UP, 2008); J. Scott Kelso, Dynamic Patterns: The Self-Organization of Brain and Behavior (Cambridge, MA: MIT, 1995); and, Esther Thelan and Linda B. Smith, A Dynamic Systems Approach to the Development of Cognition and Action (Cambridge, MA: MIT, 1994).

7. Eric R. Kandel and Larry R. Squire, "Neuroscience: Breaking Down Scientific Barriers to the Study of Brain and Mind," Unity of Knowledge: The Convergence of Natural and Human Science, eds. Antonio R. Damasio, Anne Harrington, Jerome Kagan, Bruce S. McEwen, Henry Moss, and Rashid Shaikh (New York: The Academy of Sciences, 2001) 118-35.

8. See particularly Damasio's Descartes'Error: Emotion, Reason and the Human Brain (New York: G. P. Putnam and Sons, 1994) and The Feeling of What Happens: Body and Emotion in the Making of Consciousness (New York: Harcourt Brace, 1999).

9. George Lakoff and Mark Johnson, Philosophy in the Flesh: The Embodied Mind and Its Challenge to Western Thought (New York: Basic, 1999) 20.

10. Gilles Fauconnier and Mark Turner, The Way We Think: Conceptual Blending and the Mind's Hidden Complexities (New York: Basic, 2002).

11. Gerald Edelman and Giulio Tononi, A Universe of Consciousness: How Matter Becomes Imagination (New York: Basic, 2000).

12. Elizabeth Wilson, Neural Geographies: Feminism and the Microstructure of Cognition (New York: Routledge, 1998) 6, 160.

13. Lutterbie, Toward a General Theory of Acting 8. 